\title{
PARAMETRIC ANALYSIS OF THE BUCKLING RESISTANCE OF THE SILO STEEL WALL
}

\author{
Davor Skejić \\ University of Zagreb, Faculty of Civil Engineering, Assistant Professor \\ Corresponding author: davors@grad.hr \\ Marija Cavor \\ University of Zagreb, Faculty of Civil Engineering, Student
}

\begin{abstract}
The latest final draft amendment EN 1993-4-1:2007/FprA1 brings many changes that will likely soon become valid. In this article, we assess the issue of designing steel silo walls from perspective of the proposed changes related to assessing their buckling resistance. We performed a parametric analysis, comparing the current standard, HRN EN 1993-4-1, to the proposed amendment, EN 1993-4-1:2007/FprA1, accounting for the silo fabrication quality parameter as well as variations in steel quality, wall thickness, and wall curvature radius. Our results show that the proposed amendment more realistically assesses the buckling resistance of steel silo walls. In that way the savings of material and economic benefit can be achieved easily.
\end{abstract}

Keywords: silo wall, steel, buckling, HRN EN 1993-4-1, EN 1993-4-1:2007/FprA1

\section{PARAMETARSKA ANALIZA OTPORNOSTI ČELIČNE STIJENKE SILOSA NA IZBOČIVANJE}

Sažetak: Najnoviji konačni nacrt amandmana EN 1993-4-1:2007/FprA1 donosi mnoštvo izmjena koje će, po svemu sudeći, uskoro postati važeće. U ovome članku obrađena je problematika dimenzioniranja stjenke silosa iz aspekta predloženih izmjena vezanih za procjenu otpornosti čelične stjenke silosa na izbočivanje. Parametarska analiza provedena je prema važećoj normi, HRN EN 1993-4-1, i predloženom amandmanu, EN 1993-4-1:2007/FprA1, uzimajući u obzir parametar kvalitete izrade silosa, kao i varijacije kvalitete čelika, debljine i radijusa zakrivljenosti stjenke. Dobiveni rezultati upućuju na zaključak da novi prijedlog izmjena omogućuje realniju procjenu otpornosti čelične stjenke silosa na izbočivanje. Na taj način se jednostavno može ostvariti ušteda materijala i ekonomska korist.

Ključne riječi: stjenka silosa, čelik, izbočivanje, HRN EN 1993-4-1, EN 1993-4-1:2007/FprA1 


\section{GENERAL ASPECTS OF SILO DESIGN}

The standards HRN EN 1993-4-1 [1] and HRN EN 1993-1-6 [2] discuss the issue of silo design and give designers a relatively simple calculation of silo element resistances using simplified numerical expressions. HRN EN 1993-41 [1] gives design guidance for silo structures and provides calculation rules that complement the general rules of HRN EN 1993-1-1 [3].

Part 4-1 of HRN EN 1993 [1] provides principles and application rules for the structural design of steel silos with circular or rectangular plan-forms, either free-standing or supported. However, this part of the standard only discusses the resistance and stability of the steel silos; it does not cover the following:

- $\quad$ fire resistance

- silos with internal structural subdivisions

- silos with capacities of less than 10 tons cases where special measures are necessary to limit the consequences of accidents

HRN EN 1993-4-1 [1] groups designs into three consequence classes: 1, 2, and 3, as shown in Table 1. These classes have different requirements in order to produce designs with essentially equal risk in design assessment by considering the expense and procedures necessary to reduce the risk of failure for various structures. A higher class means stricter design requirements. Table 2 gives the recommended values for the class boundaries.

The methods of designing a silo structure depend on the consequence class as follows:

- Consequence Class 3

The internal forces and moments should be determined using a validated numerical analysis (finite element shell analysis) as defined in HRN EN 1993-1-6 [2]. Plastic collapse strengths under primary stress states may be used in relation to the plastic limit state as defined in HRN EN 1993-1-6 [2].

- Consequence Class 2

For axisymmetric actions and support, one of the two following alternative analyses may be used:

- Membrane theory may be used to determine the primary stresses. The bending theory elastic expressions may be used to describe all local bending effects.

- A validated numerical analysis (e.g., finite element shell analysis) may be used, as defined in HRN EN 1993-1-6 [2].

Note: When the design loading from stored solids cannot be treated as axisymmetric, a validated numerical analysis should be used.

- Consequence Class 1

Membrane theory may be used to determine the primary stresses, with factors and simplified expressions to describe local bending effects and asymmetrical actions.

Table 1 Consequence classes, depending on size and operation [1]

\begin{tabular}{|c|c|}
\hline Consequence Class & Design situations \\
\hline Consequence Class 3 & $\begin{array}{l}\text { Silos supported by the ground or on a complete skirt extending to the ground with } \\
\text { a capacity greater than } W_{3 a} \text { tons. } \\
\text { Discretely supported silos with a capacity greater than } W_{3 b} \text { tons. } \\
\text { Silos with a capacity greater than } W_{3 c} \text { tons in which any of the following design } \\
\text { situations may occur: } \\
\text { a) eccentric discharge } \\
\text { b) local patch loading } \\
\text { c) asymmetrical filling }\end{array}$ \\
\hline Consequence Class 2 & All silos covered by HRN EN 1993-4-1 [1] and not placed in any other class. \\
\hline Consequence Class 1 & Silos with a capacity of $W_{1 \mathrm{a}}$ to $\mathrm{W}_{1 \mathrm{~b}}$ tons. \\
\hline
\end{tabular}

These consequences classes, defined in terms of silo size and operation, are not technically or economically justified. In particular, according to HRN EN 1090-2 [4], Consequence Class 3 leads to the execution class EXC3, usually specified for buildings with more than 15 floors, bridges, and crane tracks. For this execution class, reaming 
of the holes for bolts is necessary, and this is extremely harmful to competitivity. Thus, the latest final draft amendment (EN 1993-4-1: 2007/FprA1 [5]) proposes three consequence classes which are, in accordance with HRN EN 1990 [6] and HRN EN 1090-2 [4], defined in terms of the predictable consequences of failure or collapse, whether caused by human, financial, or environmental factors.

Table 2 Recommended values for class boundaries [1]

\begin{tabular}{|l|l|}
\hline Class boundary & Recommended value [tons] \\
\hline$W_{3 \mathrm{a}}$ & 5000 \\
\hline$W_{3 \mathrm{~b}}$ & 1000 \\
\hline$W_{3 \mathrm{c}}$ & 200 \\
\hline$W_{1 \mathrm{~b}}$ & 100 \\
\hline$W_{1 \mathrm{a}}$ & 10 \\
\hline
\end{tabular}

\section{DESIGN OF CYLINDRICAL SILO WALLS}

In addition to checking the global stability and static equilibrium of the whole silo structure, the cylindrical steel silo wall should be checked for the following design situations under the ultimate limit states defined in HRN EN 19931-6 [2]. The ultimate limit states are briefly described as follows (for silos in Consequence Class 1, the cyclic plasticity and fatigue limit states may be ignored):

\section{LS1: Plastic limit}

The plastic limit should be taken as the condition in which the structure's capacity to resist actions on it is exhausted because of material yielding. The resistance offered by the structure at the plastic limit state may be derived as the plastic collapse load obtained from the mechanism based on small displacement theory.

\section{LS2: Cyclic plasticity}

The limit state of cyclic plasticity should be taken as a condition in which the repeated cycles of loading and unloading produce yielding in tension and in compression at the same point, causing plastic work to be repeatedly applied to the structure. This eventually leads to local cracking because the energy absorption capacity of the material becomes exhausted.

\section{LS3: Buckling}

The limit state of buckling should be taken as the condition in which all or part of the structure suddenly develops large displacements normal to the silo wall (shell) surface. This can be caused by loss of stability under the compressive membrane or by shear membrane stresses in the silo wall; these lead to the inability to sustain any increase in the stress resultants, possibly causing total collapse. Thus, all relevant combinations of actions causing compressive membrane or shear membrane stresses in the silo wall must be accounted for.

\section{LS4: Fatigue}

The limit state of fatigue should be taken as the condition in which there are repeated cycles of increasing and decreasing stress that cause fatigue cracks.

\subsection{Buckling under axial compression}

Buckling under axial compression is one of many checks required under LS3: Buckling. Under axial compression, the design resistance must be determined at every point in the silo wall using the prescribed fabrication tolerance quality of construction, the intensity of the guaranteed co-existent internal pressure, $p$, and the circumferential uniformity of the compressive stress. In buckling-related calculations, the compressive membrane forces should be treated as positive to avoid the widespread use of negative numbers. The prescribed fabrication tolerance quality of the construction should be met as described in Table 3. 
Table 3 Fabrication tolerance quality classes [1]

\begin{tabular}{|c|c|c|}
\hline Fabrication tolerance quality of construction & Quality parameter, $Q$ & Reliability class restrictions \\
\hline Normal & 16 & $\begin{array}{c}\text { Compulsory when the silo is designed } \\
\text { according to Consequence Class 1 rules }\end{array}$ \\
\hline High & 25 & $/$ \\
\hline Excellent & 40 & $\begin{array}{c}\text { Only permitted when the silo is designed } \\
\text { according to Consequence Class 3 rules }\end{array}$ \\
\hline
\end{tabular}

HRN EN 1993-4-1 [1] provides a set of parameters and expressions for calculating the silo wall resistance against buckling under axial compression. The most recent proposals, according to final draft amendment EN 19934-1:2007/FprA1 [5], for changing the expression used to calculate the silo wall resistance against buckling are presented later. This final draft amendment, [5], was approved at the European level at the end of January 2015. It is currently in the process of ratification, and it is expected that the member states of CEN (as well as Croatia) will announce it officially by the end of April 2016.

\subsubsection{Unpressurised elastic imperfection reduction factor}

The unpressurised elastic imperfection reduction factor, $\alpha_{0}$, according to the current standard HRN EN 1993-4-1 [1] should be found as:

$$
\alpha_{0}=\frac{0,62}{1+1,91 \cdot \psi \cdot\left(\Delta w_{\mathrm{ok}} / t\right)^{1,44}}
$$

where:

$\psi$ - the stress non-uniformity parameter ( $\psi=1,0$ for circumferentially uniform compression),

$\Delta w_{\text {ok }}$ - the representative imperfection amplitude, determined as shown in [1]:

$$
\Delta w_{\mathrm{ok}}=\frac{t}{Q} \cdot \sqrt{\frac{r}{t}}
$$

where:

$t$ - the wall thickness

$Q$ - the quality parameter

$r$ - is the wall radius.

The proposed changes in EN 1993-4-1:2007/FprA1 [5] include a modified expression for determining the unpressurised elastic imperfection reduction factor:

$$
\alpha_{0}=\frac{0,83}{1+2,2 \cdot \psi \cdot\left(\Delta w_{\mathrm{ok}} / t\right)^{0,88}}
$$

\subsubsection{Plastic pressurized imperfection reduction factor}

The plastic pressurised imperfection factor, $\alpha_{\mathrm{pp}}$, should be based on the largest local internal pressure at the point being assessed and coexistent with the axial compression [1]: 


$$
\alpha_{\mathrm{pp}}=\left\{1-\left(\frac{\overline{p_{\mathrm{g}}}}{{\overline{\lambda_{\mathrm{x}}}}^{2}}\right)^{2}\right\}\left[1-\frac{1}{1,12+s^{3 / 2}}\right]\left[\frac{s^{2}+1,21{\overline{\lambda_{\mathrm{x}}}}^{2}}{s(s+1)}\right]
$$

where:

$p_{\mathrm{g}}$ - the highest design value of local internal pressure; $\overline{p_{\mathrm{g}}}=\frac{p_{\mathrm{g}} \cdot r}{t \cdot \sigma_{\mathrm{x}, \mathrm{Rcr}}}$,

$\overline{\lambda_{x}}$ - the relative slenderness of the shell, determined as $\bar{\lambda}_{\mathrm{x}}^{2}=\frac{f_{\mathrm{y}}}{\sigma_{\mathrm{x}, \mathrm{Rcr}}}$. The parameter $s$ is defined as:

$$
s=\left(\frac{1}{400}\right) \cdot\left(\frac{r}{t}\right)
$$

The proposed changes in EN 1993-4-1:2007/FprA1 [5] include a revised formula for determining the plastic pressurised imperfection reduction factor:

$$
\alpha_{\mathrm{pp}}=\left\{1-\left(\frac{\overline{p_{g}}}{{\overline{\lambda_{\mathrm{x}}}}^{2}}\right)\right\}\left[1-\frac{1}{1,12+s^{3 / 2}}\right]\left[\frac{s^{2}+1,21{\overline{\lambda_{\mathrm{x}}}}^{2}}{s(s+1)}\right]
$$

\subsubsection{Buckling reduction factor}

The buckling reduction factor, $\chi_{\mathrm{x}}$, should be determined as a function of the relative slenderness of the silo wall, $\overline{\lambda_{x}}$, from [1]:

$$
\begin{array}{lll}
\chi_{\mathrm{x}}=1,0 & \text { when } & \bar{\lambda}_{\mathrm{x}} \leq \bar{\lambda}_{0}, \\
\chi_{\mathrm{x}}=1,0-\beta \cdot\left(\frac{\bar{\lambda}_{\mathrm{x}}-\bar{\lambda}_{0}}{\bar{\lambda}_{\mathrm{p}}-\bar{\lambda}_{0}}\right)^{\eta} & \text { when } & \bar{\lambda}_{0}<\bar{\lambda}_{\mathrm{x}}<\bar{\lambda}_{\mathrm{p}}, \\
\chi_{\mathrm{x}}=\frac{\alpha}{\bar{\lambda}_{\mathrm{x}}{ }^{2}} & \text { when } & \bar{\lambda}_{\mathrm{p}} \leq \bar{\lambda}_{\mathrm{x}},
\end{array}
$$

where $\beta$ and $\eta$ may be determined by the national annex. The current Croatian national annex [7] adopts $\beta=0.6$ and $\eta=1.0$, the recommended values from [1]. However, note that EN 1993-4-1:2007/FprA1 [5] recommends that these factors should be calculated as $\beta=1-\frac{0,95}{1+1,2 \cdot\left(\Delta w_{\mathrm{ok}} / t\right)}$ and $\eta=\frac{5,4}{1+4,6 \cdot\left(\Delta w_{\mathrm{ok}} / t\right)}$.

\section{COMPARISON OF THE CURRENT AND PROPOSED EXPRESSIONS FOR CALCULATING THE CYLINDRICAL SILO WALL BUCKLING RESISTANCE}

\subsection{Numerical example}

Figure 1 shows a model of cylindrical silos, used to compare the cylindrical silo wall buckling resistances. The same silo configuration is analysed in detail in [8]. In this model, the silo wall has the thickness $t=14 \mathrm{~mm}$ and the radius $r=3000 \mathrm{~mm}$, and it is made of steel quality $\mathrm{S} 355$.

The calculations are performed for the quality parameter $Q=25$ and in accordance with the current standard HRN EN 1993-4-1 [1] and with new proposals for certain parameters related to verifying silo wall buckling [5]. 


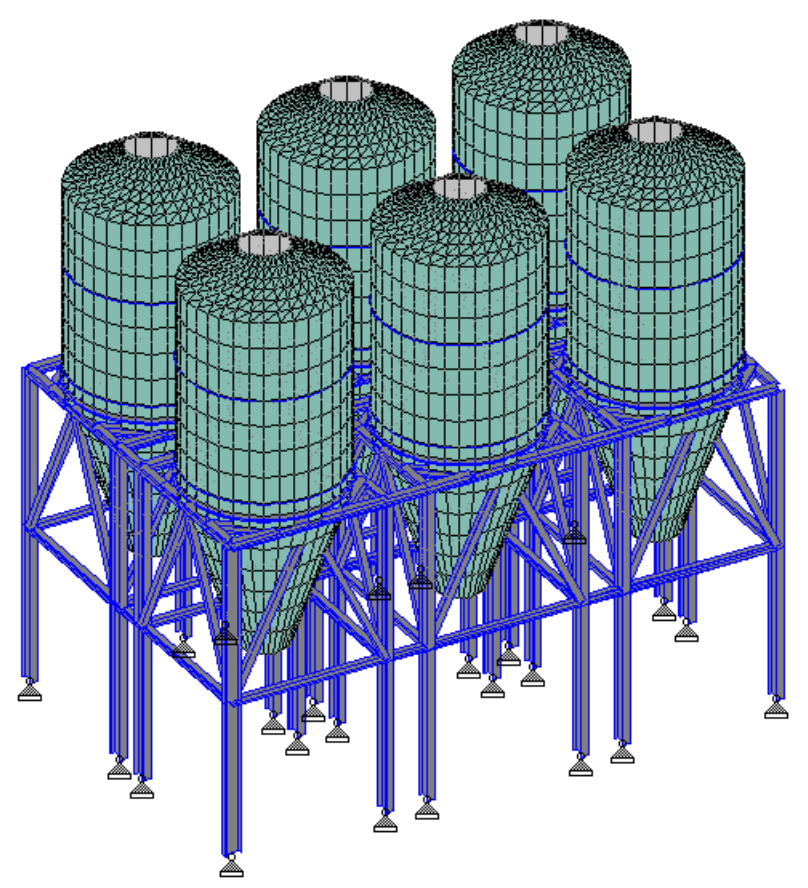

Figure $13 \mathrm{D}$ model of the cylindrical silo battery [8]

\subsubsection{Buckling under axial compression according to current standard [1]}

The elastic critical buckling stress of the isotropic wall is calculated from Eq. (1):

$$
\sigma_{\mathrm{x}, \mathrm{Rcr}}=\frac{E}{\sqrt{3 \cdot\left(1-v^{2}\right)}} \cdot \frac{t}{r}=0,605 \cdot E \cdot \frac{t}{r}=0,605 \cdot 210000 \cdot \frac{14}{3000}=593 \mathrm{~N} / \mathrm{mm}^{2} \text {. }
$$

The representative imperfection amplitude, $\Delta w_{\text {ok }}$, is determined from Eq. (2) as follows:

$$
\Delta w_{\mathrm{ok}}=\frac{0,014}{25} \cdot \sqrt{\frac{3,0}{0,014}}=8,20 \cdot 10^{-3} \mathrm{~m}
$$

The unpressurised elastic imperfection reduction factor is determined from Eq. (3):

$$
\alpha_{0}=\frac{0,62}{1+1,91 \cdot 1,0 \cdot\left(\frac{8,20 \cdot 10^{-3}}{0,014}\right)^{1,44}}=0,329
$$

The elastic pressurised imperfection factor is calculated with the minimum reliable design value of the local internal pressure $\overline{p_{S}}=\frac{p_{S} \cdot r}{t \cdot \sigma_{X, R c r}}=\frac{0,0558 \cdot 3000}{14 \cdot 593}=0,020\left(p_{s}\right.$ is taken from the analysis described in [8]), according to the following equation [1]:

$$
\alpha_{\mathrm{pe}}=\alpha_{0}+\left(1-\alpha_{0}\right) \cdot\left(\frac{\overline{p_{\mathrm{s}}}}{\overline{p_{\mathrm{s}}}+\frac{0,3}{\sqrt{\alpha_{0}}}}\right)=0,329+(1-0,329) \cdot\left(\frac{0,020}{0,020+\frac{0,3}{\sqrt{0,329}}}\right)=0,354
$$

The plastic pressurised imperfection reduction factor, $\alpha_{\mathrm{pp}}$, depends on the largest local internal pressure at the 
point being assessed, and coexistent with the axial compression [1]:

$$
\begin{aligned}
& \alpha_{\mathrm{pp}}=\left\{1-\left(\frac{\overline{p_{\mathrm{g}}}}{{\overline{\lambda_{\mathrm{x}}}}^{2}}\right)^{2}\right\}\left[1-\frac{1}{1,12+s^{3 / 2}}\right]\left[\frac{s^{2}+1,21{\overline{\lambda_{\mathrm{x}}}}^{2}}{s(s+1)}\right] \text {, where: } \\
& \overline{p_{\mathrm{g}}}=\frac{p_{\mathrm{g}}}{\sigma_{\mathrm{x}, \mathrm{Rcr}}} \cdot \frac{r}{t}=\frac{0,0585}{593} \cdot \frac{3000}{14}=0,021\left(p_{\mathrm{g}}\right. \text { is taken from the analysis described in [8]) and } \\
& s=\left(\frac{1}{400}\right) \cdot\left(\frac{r}{t}\right)=\frac{1}{400} \cdot \frac{3000}{14}=0,536 \text { and }{\overline{\lambda_{\mathrm{x}}}}^{2}=\frac{f_{\mathrm{y}}}{\sigma_{\mathrm{x}, R_{\alpha}}}=\frac{355}{593}=0,599 .
\end{aligned}
$$

Therefore, the plastic pressurised imperfection factor according to [1] is given as:

$$
\alpha_{\mathrm{pp}}=\left\{1-\left(\frac{0,021}{0,599}\right)^{2}\right\} \cdot\left[1-\frac{1}{1,12+0,536^{3 / 2}}\right] \cdot\left[\frac{0,536^{2}+1,21 \cdot 0,599}{0,536 \cdot(0,536+1)}\right]=0,418 \text {. }
$$

The buckling reduction factor, $\chi_{\mathrm{x}}$, is determined as a function of the relative slenderness of the silo wall(s), $\lambda_{\mathrm{x}}[1]$ :

$$
\begin{aligned}
& \lambda_{\mathrm{x}}=\sqrt{\frac{f_{\mathrm{y}}}{\sigma_{\mathrm{x}, R_{\alpha}}}}=\sqrt{\frac{355}{593}}=0,774, \lambda_{\mathrm{p}}=\sqrt{\frac{\alpha}{1-\beta}}=\sqrt{\frac{0,418}{1-0,6}}=1,022, \beta=0,6 \text { and } \eta=1,0: \\
& \chi_{\mathrm{x}}=1,0-0,6 \cdot\left(\frac{0,774-0,2}{1,022-0,2}\right)^{1,0}=0,581 .
\end{aligned}
$$

Accounting for the plastic imperfections, the design buckling stress [1] becomes:

$$
\sigma_{\mathrm{x}, R_{\mathrm{d}}}=\chi_{\mathrm{x}} \cdot \frac{f_{\mathrm{y}}}{\gamma_{\mathrm{M} 1}}=0,581 \cdot \frac{355}{1,1}=188 \mathrm{~N} / \mathrm{mm}^{2} \text {. }
$$

\subsubsection{Buckling under axial compression according to the latest proposals [5]}

From the calculated representative imperfection amplitude, $\Delta w_{\mathrm{ok}}$, and the elastic critical buckling stress of the isotropic silo wall, $\sigma_{\mathrm{x}, \mathrm{Rcr}}$, the unpressurised elastic imperfection reduction factor is determined, according to [5], with Eq. (3):

$$
\alpha_{0}=\frac{0,83}{1+12,2 \cdot 1,0 \cdot\left(\frac{8,20 \cdot 10^{-3}}{0,014}\right)^{0,88}}=0,350
$$

The elastic pressurised imperfection factor is based on the minimum reliable design value of the local internal pressure $\overline{p_{\mathrm{s}}}=0,020[5]$ :

$$
\alpha_{\mathrm{pe}}=\alpha_{0}+\left(1-\alpha_{0}\right) \cdot\left(\frac{\overline{p_{\mathrm{s}}}}{\overline{p_{\mathrm{s}}}+\frac{0,3}{\sqrt{\alpha_{0}}}}\right)=0,350+(1-0,350) \cdot\left(\frac{0,020}{0,020+\frac{0,3}{\sqrt{0,350}}}\right)=0,375
$$

The plastic pressurised imperfection factor, $\alpha_{\mathrm{pp}}$, depends on the highest local internal pressure at the point being assessed, and coexistent with the axial compression [5]: 


$$
\alpha_{\mathrm{pp}}=\left\{1-\left(\frac{\overline{p_{g}}}{{\overline{\lambda_{\mathrm{x}}}}^{2}}\right)\right\}\left\{1-\frac{1}{1,12+s^{3 / 2}}\right]\left[\frac{s^{2}+1,21{\overline{\lambda_{\mathrm{x}}}}^{2}}{s(s+1)}\right],
$$

where:

$\overline{p_{g}}=\frac{p_{\mathrm{g}}}{\sigma_{\mathrm{x}, R_{\sigma}}} \cdot \frac{r}{t}=\frac{0,0585}{593} \cdot \frac{3000}{14}=0,021, s=\left(\frac{1}{400}\right) \cdot\left(\frac{r}{t}\right)=\frac{1}{400} \cdot \frac{3000}{14}=0,536$, and

$\bar{\lambda}_{\mathrm{x}}^{2}=\frac{f_{\mathrm{y}}}{\sigma_{\mathrm{x}, R_{\alpha}}}=\frac{355}{593}=0,599$.

Therefore, the plastic pressurised imperfection factor according to [1] is given as:

$$
\alpha_{\mathrm{pp}}=\left\{1-\left(\frac{0,021}{0,599}\right)\right\} \cdot\left[1-\frac{1}{1,12+0,536^{\frac{3}{2}}}\right] \cdot\left[\frac{0,536^{2}+1,21 \cdot 0,599}{0,536 \cdot(0,536+1)}\right]=0,402
$$

Finally, according to [5], the buckling reduction factor $\chi_{\mathrm{x}}$ is determined as a function of the relative slenderness of the silo wall, $\lambda_{\mathrm{x}}[1]$ :

$$
\begin{aligned}
& \beta=1-\frac{0,95}{1+1,2 \cdot\left(w_{\mathrm{ok}} / t\right)}=1-\frac{0,95}{1+1,2 \cdot\left(\frac{8,20 \cdot 10^{-3}}{0,014}\right)}=0,442, \\
& \eta=\frac{5,4}{1+4,6 \cdot\left(w_{\mathrm{ok}} / t\right)}=\frac{5,4}{1+4,6 \cdot\left(\frac{8,20 \cdot 10^{-3}}{0,014}\right)}=1,462, \\
& \lambda_{\mathrm{x}}=\sqrt{\frac{f_{\mathrm{y}}}{\sigma_{\mathrm{x}, \mathrm{R}_{\alpha}}}}=\sqrt{\frac{355}{593}}=0,774 \text { and } \lambda_{\mathrm{p}}=\sqrt{\frac{\alpha}{1-\beta}}=\sqrt{\frac{0,402}{1-0,442}}=0,849, \\
& \chi_{\mathrm{x}}=1,0-0,442 \cdot\left(\frac{0,774-0,2}{0,849-0,2}\right)^{1,462}=0,631 .
\end{aligned}
$$

By accounting for the plastic imperfections design buckling stress according to [5]:

$$
\sigma_{\mathrm{x}, R_{\mathrm{d}}}=\chi_{\mathrm{x}} \cdot \frac{f_{\mathrm{y}}}{\gamma_{\mathrm{M} 1}}=0,631 \cdot \frac{355}{1,1}=204 \mathrm{~N} / \mathrm{mm}^{2} \text {. }
$$

\subsubsection{Discussion}

The new final draft amendment of HRN EN 1993-4-1 [1] gives a $9 \%$ higher silo wall buckling resistance than does the current standard, as shown in Table 4. However, to draw more general conclusions, we also performed a parametric analysis, presented as follows.

Table 4 Comparison of results from the current standard and proposed amendment

\begin{tabular}{|c|c|}
\hline Standard & $\sigma_{x, R d}\left[\mathrm{~N} / \mathrm{mm}^{2}\right]$ \\
\hline HRN EN 1993-4-1 [1] & 188 \\
\hline EN 1993-4-1:2007/FprA1 [5] & 204 \\
\hline$[5] /[1]$ & 1.09 \\
\hline
\end{tabular}




\subsection{Parametric analysis}

The following sets of parameters are included in the parametric analysis: the steel quality, the wall thickness $t$, the wall curvature radius $r$, and the quality parameter $Q$. The steel used in the analysis has the following qualities: $S$ 235 , S 275, S 355, and S 460. The wall thickness is $4-20 \mathrm{~mm}$, while the effect of the curvature radius is considered for three cases: $r=2 \mathrm{~m}, r=3 \mathrm{~m}$, and $r=4 \mathrm{~m}$. We also account for all quality parameters given in [1] $(Q=16,25$, and 40).

\subsubsection{Effect of steel quality}

Figure 2 shows how the steel quality affects the silo wall buckling resistance, according to [1] and [5].
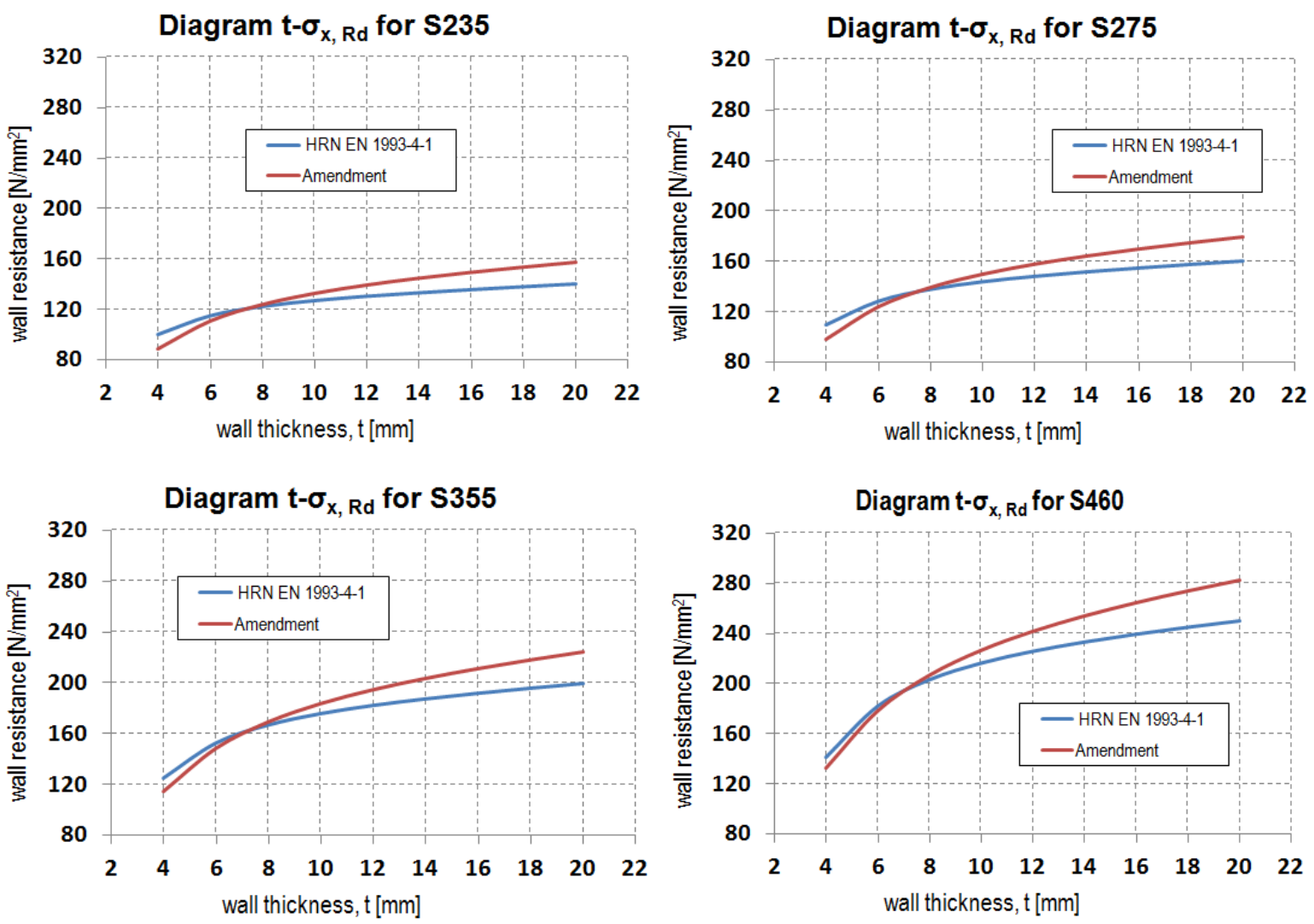

Figure 2 The effect of steel quality on silo wall buckling resistance, according to [1] and [5]

The proposed amendment [5] gives (max. 13\%) lower resistances until the wall thickness exceeds $\sim 8 \mathrm{~mm}$, after which it gives higher values. At a wall thickness of $20 \mathrm{~mm}$, the proposed amendment gives a resistance $12 \%$ (for S235 and S275) to 13\% (for S355 and S460) higher than the one calculated according to the current standard [1].

\subsubsection{Effect of silo wall curvature radius}

Figure 3 shows how the wall curvature radius affects the silo wall buckling resistance according to [1] and [5]. The proposed amendment [5] gives (max. 12\%) lower resistances until the wall thickness exceeds $\sim 6 \mathrm{~mm}$ for $r=2 \mathrm{~m}$, $\sim 8 \mathrm{~mm}$ for $r=3 \mathrm{~m}$, and $\sim 10 \mathrm{~mm}$ for $r=4 \mathrm{~m}$, after which it gives higher values. At a wall thickness of $20 \mathrm{~mm}$, the proposed amendment gives a resistance 10\% (for $r=4 \mathrm{~m}$ ) to 16\% (for $r=2 \mathrm{~m}$ ) higher than that given by the current standard [1]. 

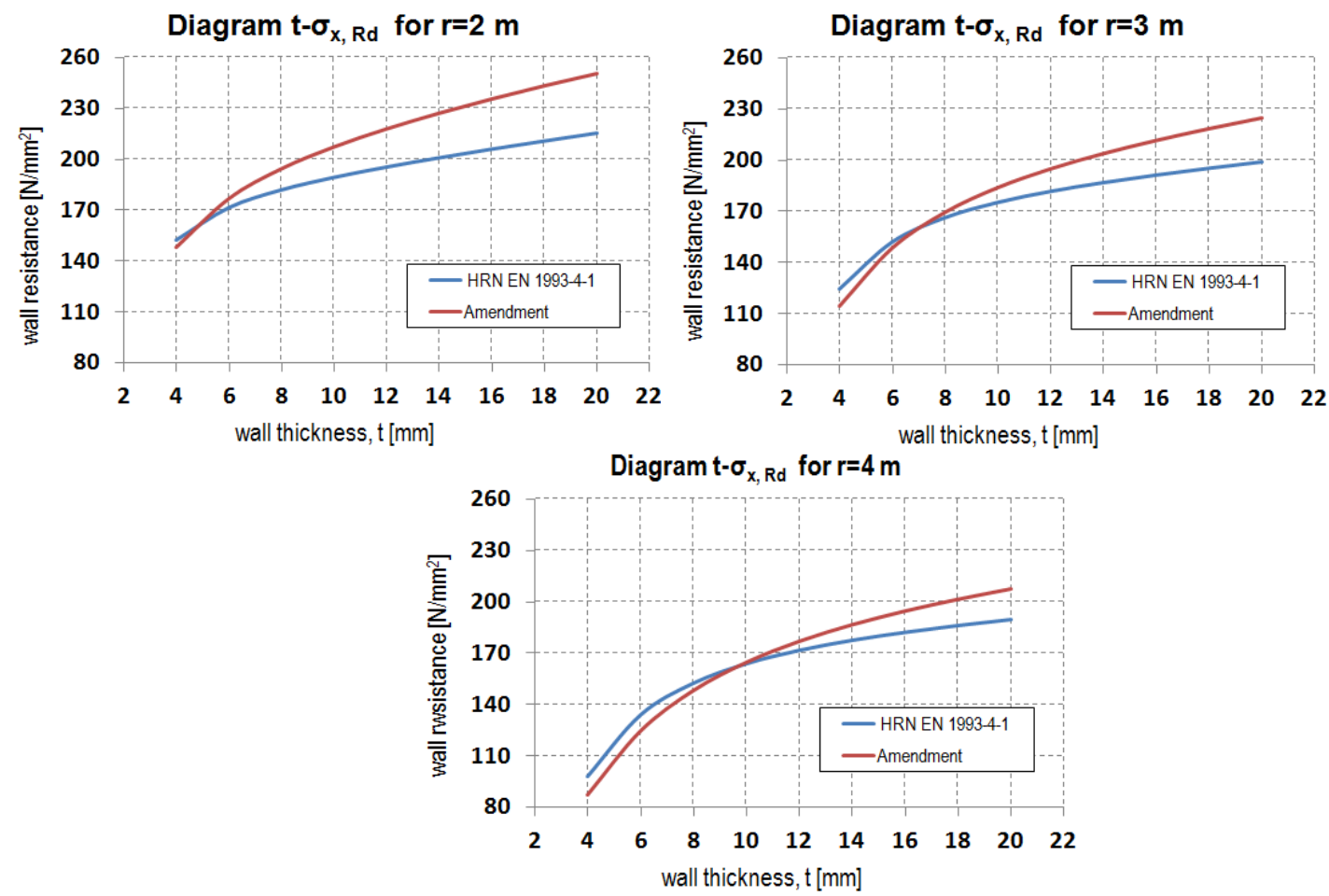

Figure 3 The effect of curvature radius on silo wall buckling resistance, according to [1] and [5]

\subsubsection{Effect of quality parameter $Q$}

Figure 4 shows how the silo quality parameter affected the silo wall buckling resistance according to [1] and [5]. The proposed amendment [5] gives (max. 16\%) lower resistances until the wall thickness exceeds $\sim 14 \mathrm{~mm}$ for $Q$ $=16, \sim 8 \mathrm{~mm}$ for $Q=25$, and $\sim 6 \mathrm{~mm}$ for $Q=40$, after which it begins to give higher values. At a wall thickness of $20 \mathrm{~mm}$, the proposed amendment gives a resistance $4 \%$ (for $Q=16$ ) to $19 \%$ (for $Q=40$ ) higher than that given by the current standard [1].
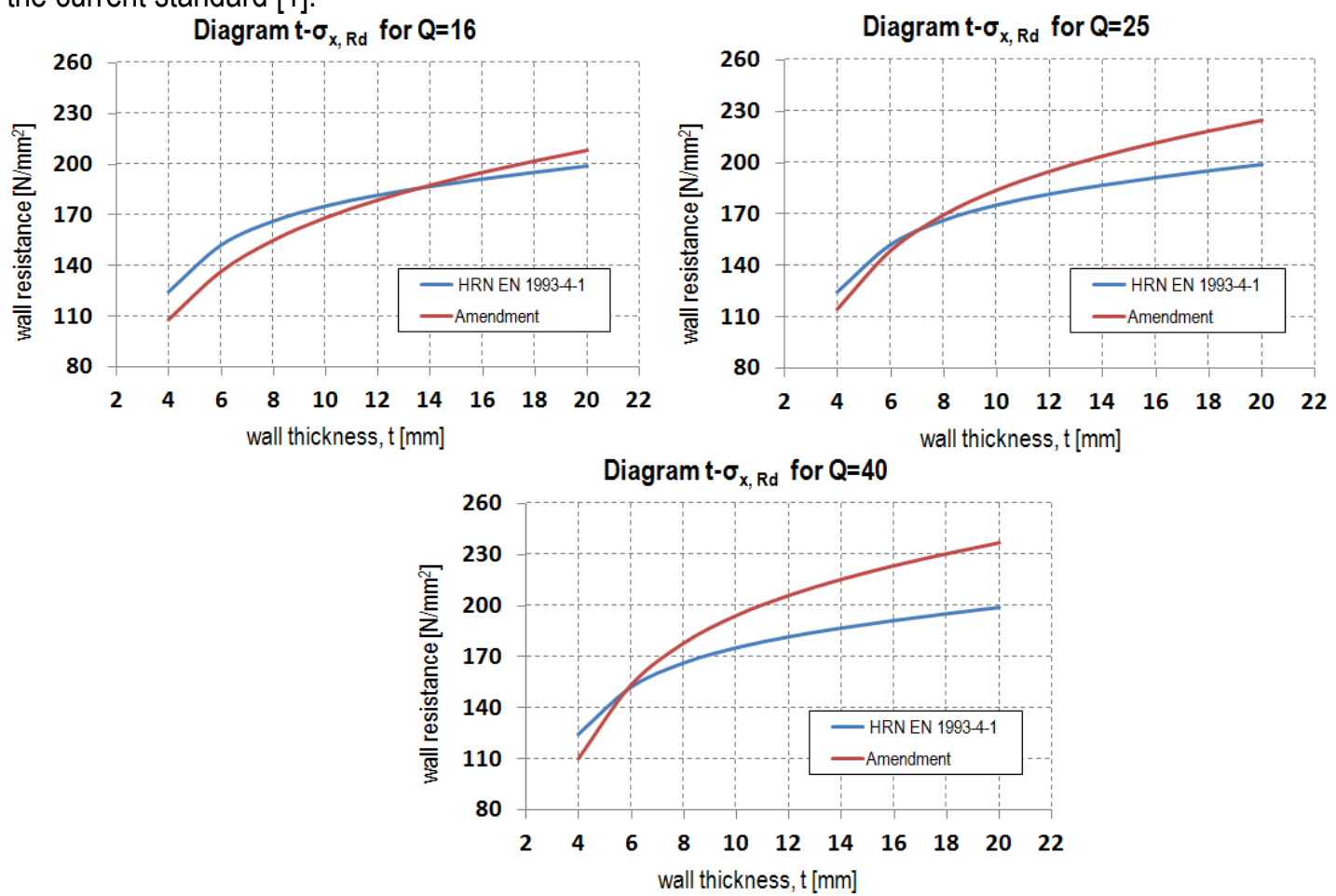

Figure 4 The effect of quality parameter on the silo wall resistance to buckling, according to [1] and [5] 


\section{CONCLUSION}

The proposed changes to HRN EN 1993-4-1 [1], given in the latest final draft amendment EN 1993-4-1:2007/FprA1 [5], will by all odds become valid at the end of April 2016.

Using parametric studies, we showed that the amendments related to calculating the buckling resistance of silo steel walls can give higher resistances. This fact allows for lower material consumption, making these designs more economical. However, we also showed that these savings can only be achieved by carefully selecting the steel quality, wall thickness, and wall curvature radius, as well as the silo fabrication tolerance quality. Finally, to optimized design of a cylindrical silo battery, all changes introduced by the new amendment [5] should be considered in detail.

\section{References:}

[1] HRN EN 1993-4-1, Eurocode 3: Design of steel structures - Part 4-1: Silos (EN 1993-4-1:2007/AC:2009), HZN, 2011.

[2] HRN EN 1993-1-6, Eurocode 3: Design of steel structures - Part 1-6: Strength and stability of shell structures (EN 1993-1-6:2007+AC:2009), HZN, 2014.

[3] HRN EN 1993-1-1, Eurocode 3: Design of steel structures - Part 1-1: General rules and rules for buildings (EN 1993-1-1:2005+AC:2006), HZN, 2008.

[4] HRN EN 1090-2: Execution of steel and aluminium structures - Part 2.: Technical requirements for steel structures (EN 1090-2:2008+A1:2011), HZN, 2011.

[5] EN 1993-4-1:2007/FprA1: Eurocode 3: Design of steel structures - Part 4-1: Silos / The final draft amendments, CEN, 2014.

[6] HRN EN 1990: Eurocode: Basis of structural design (EN 1990:2002+A1:2005+ A1:2005/AC:2010), HZN, 2011.

[7] HRN EN 1993-4-1/NA, Eurocode 3: Design of steel structures - Part 4-1: Silos - Nacional annex, HZN, 2014.

[8] Cavor, M., 2014: Project of cylindrical conical silos for iron ore storage, Graduate work, Faculty of Civil Engineering, University of Zagreb, Zagreb, mentor: Skejić, D. 